\title{
GENERATIVE DESIGN SOFTWARE AND DIFFERENT APPROACHES
}

\author{
Gonzalo Acosta-Zazueta ${ }^{1 *}$, Jorge Alcaide-Marzal ${ }^{2}$, José Antonio Diego-Más ${ }^{3}$ \\ ${ }^{1}$ Mr., Universitat Politècnica de València, SPAIN, gonacza@etsid.upv.es \\ ${ }^{2}$ Prof. Dr., Universitat Politècnica de València, SPAIN, jalcaide@dpi.upv.es \\ ${ }^{3}$ Prof. Dr., Universitat Politècnica de València, SPAIN, jodiemas@dpi.upv.es \\ ${ }^{*}$ Corresponding author
}

\begin{abstract}
The use of computers for design is not something new, it has been implemented mostly since the 80's with good results when it comes to getting to represent a design visually. However, the progress of new design paradigms with high construction potential, such as Generative Design, have made the companies who create CAD systems, see the necessity to generate specialised software or integrate and adapt modules that consider these new design modalities. A growing number of fields include these creation techniques within their workflow when developing products with higher novelty and originality. The aim of this work is to create a brief compendium of software that addresses generative design in its different modes of use, its most frequent applications, and the possible use modules or plugins. Also, a search is made of existing works in the literature that address the implementation of computer systems and new design techniques with wide variability of results, stating a wide variety of adoptions in different fields and quoting some significant works. In addition, based on the information collected in this research process, design tools used for generative design are indicated, documenting the spread and trend of use of the main design programs for the development of studies related to generative design.
\end{abstract}

Keywords: Generative design, computer aided design, computer design tools.

\section{INTRODUCTION}

The use of computers in design is not a new topic, it has been used for a couple of decades; however, it is recognized that the use of computer systems has only been limited as a drawing and storage element and has not been used as an instrument of creation. Here it is important to specify the difference between both concepts, the process of drawing consists of graphically capturing an idea already conceived in advance. On the other hand, the creation process corresponds to the realization of an object from scratch directly into the computer system.

Currently the performance of computer systems allows the processing of a large amount of data, offering high potential as an instrument for exploring solutions (Krish, 2011); no longer working only with the 
definition or resolution of the object's geometry, but with the data related to the specific rules that a computer can process and interpret. The use of generative design with this computing potential, allows to deal with the design challenge at a level that human capacity would be difficult to emulate.

Generative Design (GD) constitutes a different way of breaking creative blockings by letting the computer generate alternatives. The designer can explore a much wider range of possible product designs in a comparatively lower time. It is a relatively new discipline in some fields as industrial design. It is more widely spread in architecture design, where the algorithmic nature of the generated geometry fits perfectly into the modern building aesthetics.

\section{THE SOFTWARE}

In the search for generative tools, a large part of them focuses on shape optimization, which is one of the applications of GD, but not the only one. The main objective of the GD is to create shapes by applying restrictions, indicated to the computer to search for shapes that comply with them.

Topological optimization is often confused with GD, so it is important to note the differences between these design tools. We can define that topological optimization is a subclass of what generative design can do, since what this tool mainly does is optimize a design, made by a traditional CAD system, through algorithmic processing. In most of the times, topological optimization is used to remove material from the object, lighten it, but keeping its performance characteristics. This, as such, is not the generation of a design, but only the improvement of a design that already has its main morphology established. Instead, GD begins by establishing the constraints of the object to design, and based on these constraints the computer, which has no preconceived idea of shape, generates hundreds or thousands of design solutions. This is a creation process, which can be accompanied by a form optimization if it is indicated in the established restrictions.

For this advantage that generative design brings, many companies with extensive experience in computeraided design, such as Autodesk, Dassault Systèmes or Siemens, have made efforts in the research and development of specialized software.

From Autodesk we can find a wide variety of software that allow the generative design for an amplitude of sectors. Inventor and Fusion 360, which specialize more in general optimization of topology, Maya in animation, Revit and Dynamo Studio focus on the construction sector, Netfabb for lattice and surface optimization, and Within which also focuses on the optimization of surfaces but canalized to medical implants.

Dassault Systèmes has implemented generative design modules in its SolidWorks and CATIA using Topology Study Tool, TOSCA, Driven Generative Designer and Generative Shape Design. Siemens also develops topology optimization and advanced geometry creation through its NX and Solid Edge software.

It is also possible to find other computer tools specialized in GD, such as Generate TrueSOLID by Frustum Inc. for mechanical and product design. Houdini and Blender 3D for animation and modeling. SolidThinking Inspire by Altair provides solutions for surface optimization. nTopology and Element for advanced manufacturing. Creo by PTC Corporation, MSC Apex Generative Design, Onshape and Paramatters for general optimization of topology and advanced manufacturing. Archicad and Microstation specialize in the field of architecture. It should be noted that some of these tools can be integrated into computer-aided design software from Autodesk, Siemens or Dassault Systèmes.

There are other free resource and experimental tools such as Automake Software 1 for objects creation combining generative systems with craft knowledge and digital production technologies, this tool is an online 3D generative design software. On the other hand, NodeBox is an application for the design of patterns and 2D graphics. Likewise, there is Dynamo free version which is an open-source graphical programming for design in Autodesk Revit.

To conclude this brief extract of software with a presence in the generative design (Table 1), we should certainly mention Grasshopper for Rhinoceros, which recently has also been integrated into the new RhinoGrasshopper-Archicad connection in its 21 version.

\footnotetext{
${ }^{1}$ Automake http://www.automake.co.uk
} 
Table 1. Software for GD.

\begin{tabular}{|c|c|c|c|}
\hline Developer & Software & Focus on & Plugin or Module \\
\hline Altair & SolidThinking Inspire & Topology optimization & \\
\hline Autodesk & Fusión 360 & $\begin{array}{c}\text { Topology optimization and } \\
\text { product design }\end{array}$ & \\
\hline Autodesk & Netfabb & $\begin{array}{l}\text { Lattice and surface } \\
\text { optimization }\end{array}$ & \\
\hline Autodesk & Dynamo Studio & Building industry & \\
\hline Autodesk / Mode Lab & Revit & Building industry & Dynamo \\
\hline Autodesk & Inventor & Optimization of structures & $\begin{array}{c}\text { Shape Generator / } \\
\text { integration with Fusion } 360\end{array}$ \\
\hline Autodesk & Within & $\begin{array}{l}\text { Optimization of surfaces } \\
\text { and medical implants. }\end{array}$ & \\
\hline Autodesk & Maya & Animations & Hypergraph \\
\hline Bentley & Microstation & $\begin{array}{l}\text { Architecture and } \\
\text { Engineering }\end{array}$ & GenerativeComponents \\
\hline Dassault Systèmes & SolidWorks & Surface optimization & Topology Study and Tosca \\
\hline Dassault Systèmes & CATIA & Surface optimization & $\begin{array}{c}\text { Driven Generative Designer } \\
\text { and Generative Shape } \\
\text { Design }\end{array}$ \\
\hline $\begin{array}{l}\text { Experimental Media } \\
\text { Research Group }\end{array}$ & NodeBox & Patterns & \\
\hline Frustum Inc. & Generate & $\begin{array}{l}\text { Mechanical design and } \\
\text { product design }\end{array}$ & TrueSolid \\
\hline Graphisoft & Archicad & Architecture & Grasshopper \\
\hline McNell \& Associates & Rhinoceros & $\begin{array}{c}\text { Topology optimization and } \\
\text { product design }\end{array}$ & Grasshopper \\
\hline MSC Software & $\begin{array}{c}\text { MSC Apex } \\
\text { Generative Design }\end{array}$ & Topology optimization & \\
\hline nTopology & Element & Optimization of structures & \\
\hline nTopology & nTopology & $\begin{array}{l}\text { Mechanical design and } \\
\text { product design }\end{array}$ & \\
\hline Onshape Inc. & Onshape & Topology optimization & \\
\hline Open-source & Blender 3D & Animation and modeling & $\begin{array}{l}\text { BY-GEN generative design } \\
\text { addon and }\end{array}$ \\
\hline PTC Corporation & Creo & Topology optimization & $\begin{array}{c}\text { Creo Generative Design } \\
\text { Extension, } \\
\text { Modeling and Topology } \\
\text { Optimization Extension }\end{array}$ \\
\hline SideFX & Houdini & Animations & \\
\hline Siemens & NX (Unigraphics) & Topology optimization & \\
\hline Siemens & Solid Edge ST10 & Topology optimization & \\
\hline $\begin{array}{l}\text { University } \\
\text { Falmouth, Dollege } \\
\text { Marshall }\end{array}$ & Automake & Craft/object designs & \\
\hline
\end{tabular}

\subsection{The use of generative software in research works}

Although generative design and the use of the computer have become intrinsic, it is worth documenting some of the different applications it has had over the years. Reviewing some existing works in the literature it is possible to find studies that address the implementation of computer from many fields and varied approaches. These can range from product design, architectural, engineering, art, etc. A large database was created, but only mention is made of a few where the use of the computer is relevant.

For example, for product design, in (Chen \& Owen, 1998) a system is proposed based on the modification of 
primitives by means of different rules of decomposition, joining, or redimension of simple shapes into more complexes ones representing the whole product. (Hsiao \& Wang, 1998) present another system based in semantic information, which is used to derive product shapes through b-splines and interactively manipulate the results.

In the architecture field the following works can be quoted. Hemberg \& O'Reilly proposed Genr8, which is a software tool for architects (Hemberg \& O'Reilly, 2004). This proposal generates surfaces in the CAD tool Maya environment from grammar-based generative growth model. The generated surfaces are created by a Hemberg Extended Map L-System (HEMLS), which is a more complex version of the Lindenmayer System (L-system). In other research, EduDesign, an interactive generative system for architecture design, was implemented as a 3D Studio plugin (Dincer, Tong, \& Cagdas, 2012). In the research of Prats, Earl, Garner, \& Jowers a model for exploration of shapes in new designs at early stages is presented (M Prats, Earl, Garner, \& Jowers, 2006). Besides of this, the task of detecting shapes is approached in (Miquel Prats, Lim, Jowers, Garner, \& Chase, 2009) by means of studying sketches and shape transformation through shape rules technique.

It is possible to find research papers whose point out some needs and challenges that computer application brings in the different stages of design. For example, Smyth \& Edmonds point to the use of threedimensional shape grammars as a necessity. In similar way, S. Chase denotate the development of design tools such as generative systems, has been slow due to the lack of good interaction between the user and the system (Scott C Chase, 2002). In (Lin \& Lee, 2013) usability methods and tools in generative design are analyzed through the Rhinoceros software and the Grasshopper plugin.

For its part, (Tsai, Chen, Tsai, \& Hung, 2010) combine the principles of fuzzy set theory, the shape-blending method and genetic algorithms to assist the designer at early stages of design into a computer-aided environment. It is in this environment that (Talbott, 2007) pointed out with several problems caused by designer-computer interaction.

Although the use of the computer is not a commonly used element in conceptual stages, it has high potential, as can be seen in the work of (Neill et al., 2010) where an interactive complement for Blender 3D was used, turning the use of the computer into a tool to increase human creativity.

The use of computer-aided design is used mainly in the detailed design stage, rather than in the conceptual design stage, as is mentioned above. This is pointed out in the work of (Kielarova, Pradujphongphet, \& Bohez, 2015), in this research explores an application in jewelry to bring the benefits of CAD to the early stages of the creative design process through a GD system.

In addition to these investigations, others can be quoted that point the use of computer for different purposes in GD. Like the work of Rubaiat Habib Kazi, here the gap between conceptual design and detailed design using CAD is addressed (Kazi, Grossman, Cheong, Hashemi, \& Fitzmaurice, 2017). This research presented DreamSketch, a 3D design interface that combines the qualities of sketching and computer design with generative algorithms. Kazi quote other technological solutions that deal with this issue, such as 3D6B Editor (Kallio, 2005), the mental canvas (Dorsey, Xu, Smedresman, Rushmeier, \& McMillan, 2007), Insitu (Paczkowski, Kim, \& Morvan, 2011), and Tilt Brush, the innovative virtual reality drawing app developed by Google. In the same early stage of design to explore the conceptual form, is the work of Kwon, Gross, \& YiLuen who propose the interactive system ArchiDNA as a solution (Kwon, Gross, \& Yi-Luen Do, 2009).

In the work of (Grasl \& Economou, 2011) a plugin implemented in Rhinoceros called GRAPE is introduced. In recent research works plugins for software like Revit, Autocad and Rhino5 are in different stages of development.

As in the work of (Sansri \& Kielarova, 2018), where a GD plugin called Octupus is also used. This plugin is installed in Grasshopper, which runs on the Rhinoceros program. the case study here is a clip brooch jewelry modeling. Or, in the recent research by (Wang, Chen, Janssen, \& Ji, 2020), where a series of tools for architectural design are introduced, in order to assist in the exploration of design alternatives through evolutionary design.

With this bibliographic search, it has also been found the Rhinoceros software and Grasshopper are widely used; some research in which it is adopted: ceramic tableware (Castro E Costa \& Duarte, 2013), buildings (Abdullah \& Kamara, 2013), mobile case (Lee \& Lin, 2014), Free-form surface (Huang \& Li, 2014), perfume bottle (Kielarova \& Sansri, 2016), chinese lattice (Ji, 2016), urban design (Koenig, Miao, Knecht, Buš, \& MeiChih, 2017). 


\section{BRIEF SOFTWARE USAGE TRENDS}

Regarding the technological aspect, it is important to note that GD is a method that uses computational capabilities to support designers and (or) automate some parts of design process (Singh \& Gu, 2011). Here, visual programming languages as Grasshopper, are becoming popular due to its ease of use and its rapid learning. The research of (Leitão, Santos, \& Lopes, 2012) is a comparative study between modern textual programming languages and visual programming languages.

The main difference between generative design method and traditional CAD system is that GD techniques focus on exploring the change of shape through controlling the parameters (Lin \& Lee, 2013). As well, Chase (S C Chase, 2005) argues that traditional CAD design lacks the exploratory potential of GD, CAD systems act as design aids, where the user enters and manipulates forms directly, in a different way from generative computing whose power to explore solutions is much broader. However, an effective generative design system must have a mechanism of communicative fluidity between the designer and the system (Miquel Prats et al., 2009).

There is a large variety of software that allow, in one way or another, the interaction of the user to generative design; Fig. 6 shows the main CAD tools used in works documented in this paper. The use of Rhinoceros / Grasshopper is remarkable in this research.

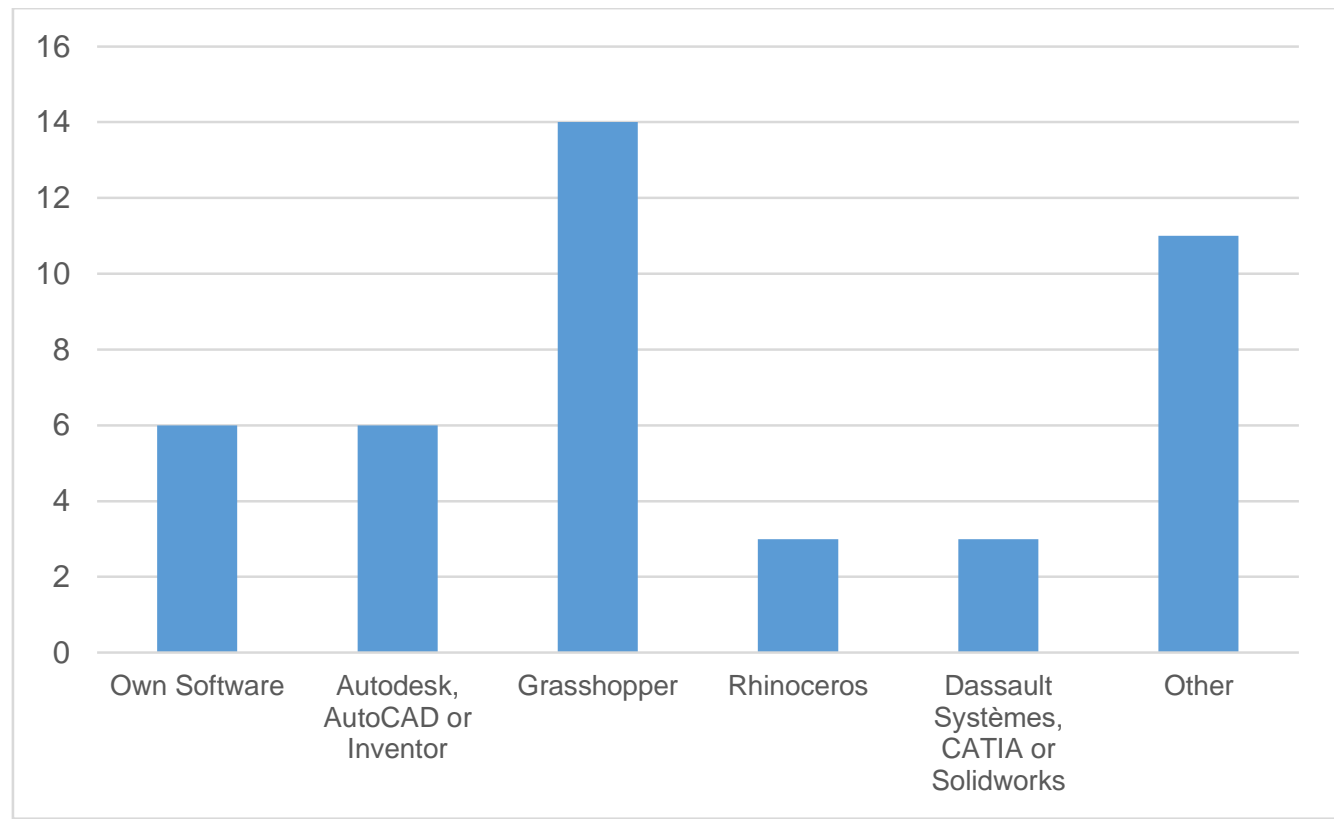

Other: Solidworks, Unigraphics, Microstation, Blender 3D Software, EduDesign (3D Studio plugin), CATIA, Trimble Sketchup, XTreme ToolketPro 2008, Maya, CityEngine.

Figure 1. CAD tools used for GD in research works.

To sustain this trend of Grasshopper, it is possible to quote the research of Lin \& Lee, who explain that the extendable programming environment of Grasshopper offers the freedom to create a wide-range of possible design solutions based on a defined solution space, instead of building a final fixed digital model (Lin \& Lee, 2013), Likewise in the work of (Leitão et al., 2012) admit that visual programming languages as Grasshopper are more productive and motivating for beginners. Reasons why the popularity of Grasshopper in recent research can be inferred, Fig. 7.

As possible future work, the opportunity to make a comparison between the software that allows generative design is interesting, in order to identify the main functional differences that each one of them might present. In addition, to carry out an analysis of the advantages and disadvantages that one may have over the others in different fields of use. 


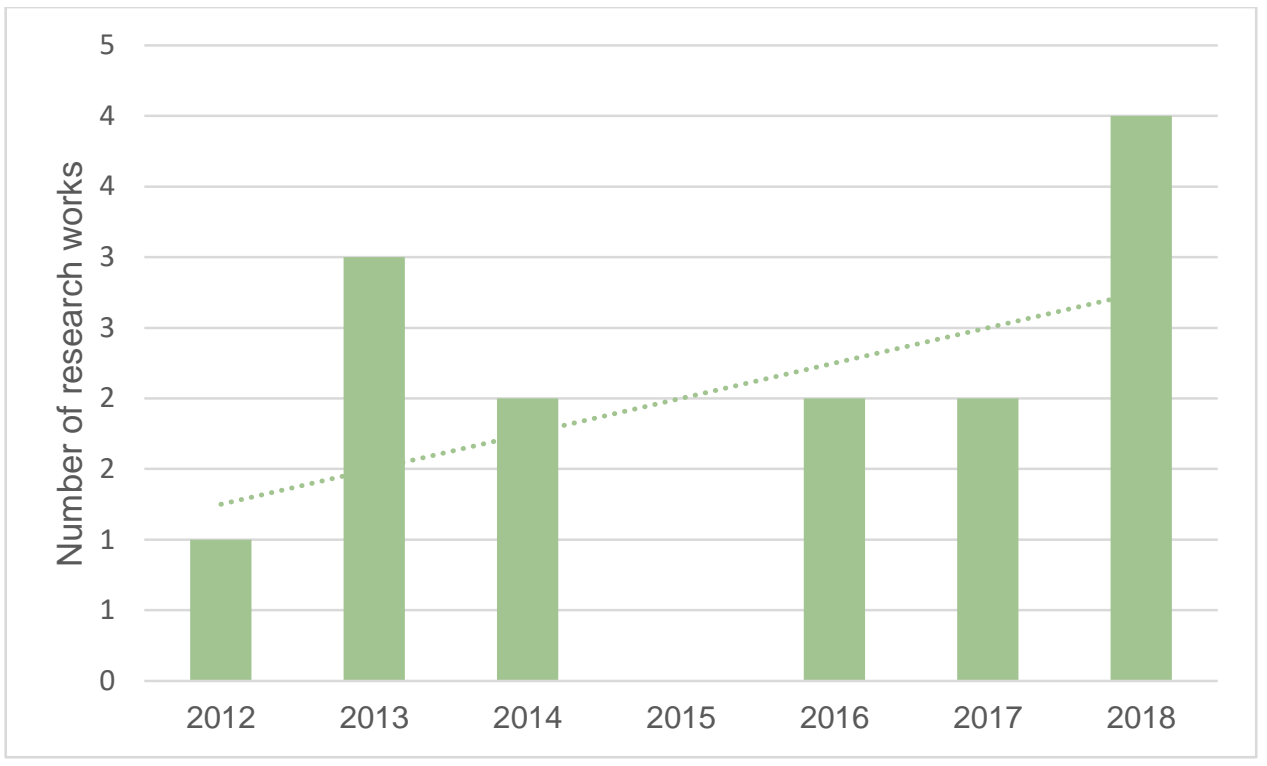

Figure 2. Tendency line in the use of Grasshopper by years.

\section{CONCLUSIONS}

In this work, a large part of the existing software that allows generative design was documented, in addition, it was indicated if these software work individually or with the implementation of plugins and modules. On the other hand, a summary was made of several papers that address the use of computer to create design variations. Based on the information collected, it was able to provide some trend insights on the use of these software in research works related to assisted design.

\section{REFERENCE LIST}

Abdullah, H. K., \& Kamara, J. M. (2013). Parametric Design Procedures: A New Approach to GenerativeForm in the Conceptual Design Phase. Aei 2013, (April), 334-343. https://doi.org/10.1061/9780784412909.032

Castro E Costa, E., \& Duarte, J. P. (2013). Mass customization of ceramic tableware through digital technology. Green Design, Materials and Manufacturing Processes - Proceedings of the 2nd International Conference on Sustainable Intelligent Manufacturing, SIM 2013, 467-471. https://doi.org/10.1201/b15002-91

Chase, S C. (2005). Generative design tools for novice designers: Issues for selection. Automation in Construction, 14(6), 689-698.

Chase, Scott C. (2002). A model for user interaction in grammar-based design systems. Automation in Construction, 11(2), 161-172. https://doi.org/10.1016/S0926-5805(00)00101-1

Chen, \& Owen, C. L. (1998). A study of computer-supported formal design. Design Studies, 19(3), 331-359. https://doi.org/10.1016/S0142-694X(98)00002-7

Dincer, A. E., Tong, H., \& Cagdas, G. (2012). An Interaction form Generation Tool: EduDesign. Procedia Social and Behavioral Sciences, 51, 74-78. https://doi.org/10.1016/j.sbspro.2012.08.121

Dorsey, J., Xu, S., Smedresman, G., Rushmeier, H., \& McMillan, L. (2007). The mental canvas: A tool for conceptual architectural design and analysis. Proceedings - Pacific Conference on Computer Graphics and Applications, 201-210. https://doi.org/10.1109/PG.2007.62

Grasl, T., \& Economou, A. (2011). GRAPE: Using graph grammars to implement shape grammars. Proceedings of the 2011 Symposium on Simulation for Architecture and Urban Design.

Hemberg, M., \& O'Reilly, U.-M. (2004). Extending Grammatical Evolution to Evolve Digital Surfaces with 
Genr8. Genetic Programming 7th European Conference, EuroGP 2004, Proceedings, 3003, 299-308. https://doi.org/10.1007/978-3-540-24650-3_28

Hsiao, S.-W., \& Wang, H.-P. (1998). Applying the semantic transformation method to product form design. Design Studies, 19(3), 309-330. https://doi.org/10.1016/S0142-694X(98)00009-X

Huang, Y., \& Li, J. Y. (2014). Generative product design inspired by natural information. Lecture Notes in Computer Science (Including Subseries Lecture Notes in Artificial Intelligence and Lecture Notes in Bioinformatics), 8521 LNCS(PART 1), 583-593. https://doi.org/10.1007/978-3-319-07731-4_57

Ji, G. (2016). Digital generation of chinese ice-ray lat- tice designs. (2013), 85-94.

Kallio, K. (2005). 3D6B Editor: Projective 3D Sketching with Line-Based Rendering. 2nd Eurographics Workshop on Sketch-Based Interfaces and Modeling, 1-7. https://doi.org/10.2312/SBM/SBM05/073079

Kazi, R. H., Grossman, T., Cheong, H., Hashemi, A., \& Fitzmaurice, G. (2017). DreamSketch: Early Stage 3D Design Explorations with Sketching and Generative Design. Proceedings of the 30th Annual ACM Symposium on User Interface Software and Technology - UIST '17, 401-414. https://doi.org/10.1145/3126594.3126662

Kielarova, S. W., Pradujphongphet, P., \& Bohez, E. L. J. (2015). New interactive-generative design system: Hybrid of shape grammar and evolutionary design - An application of jewelry design. Lecture Notes in Computer Science (Including Subseries Lecture Notes in Artificial Intelligence and Lecture Notes in Bioinformatics). https://doi.org/10.1007/978-3-319-20466-6_33

Kielarova, S. W., \& Sansri, S. (2016). Shape Optimization in Product Design Using Interactive Genetic Algorithm Integrated with Multi-objective Optimization. 10607, 76-86. https://doi.org/10.1007/978-3319-69456-6

Koenig, R., Miao, Y., Knecht, K., Buš, P., \& Mei-Chih, C. (2017). Interactive urban synthesis: Computational methods for fast prototyping of urban design proposals. Communications in Computer and Information Science, 724, 23-41. https://doi.org/10.1007/978-981-10-5197-5_2

Krish, S. (2011). A practical generative design method. Computer-Aided Design, 43(1), 88-100. https://doi.org/10.1016/j.cad.2010.09.009

Kwon, D. Y., Gross, M. D., \& Yi-Luen Do, E. (2009). ArchiDNA: An interactive system for creating 2D and 3D conceptual drawings in architectural design. CAD Computer Aided Design, 41(3), 159-172. https://doi.org/10.1016/j.cad.2008.07.007

Lee, L. C. J., \& Lin, M. H. (2014). Experimental research in applying generative design and 3D printers in user participating design. Lecture Notes in Computer Science (Including Subseries Lecture Notes in Artificial Intelligence and Lecture Notes in Bioinformatics), 8517 LNCS(PART 1), 296-307. https://doi.org/10.1007/978-3-319-07668-3_29

Leitão, A., Santos, L., \& Lopes, J. (2012). Programming Languages for Generative Design: A Comparative Study. International Journal of Architectural Computing, 10(1), 139-162. https://doi.org/10.1260/14780771.10.1.139

Lin, M.-H., \& Lee, L.-C. (2013). An Experimental Study for Applying Generative Design to Electronic Consumer Products. Part IV LNCS, 8015, 392-401. https://doi.org/10.1007/978-3-642-39253-5_43

Neill, M. O., Mcdermott, J., Swafford, J. M., Byrne, J., Hemberg, E., Brabazon, A., \& Engineering, C. (2010). Evolutionary design using grammatical evolution and shape grammars : designing a shelter. Int. J. Design Engineering, 3(1), 4-24. https://doi.org/doi:10.1504/IJDE.2010.032820

Paczkowski, P., Kim, M., \& Morvan, Y. (2011). Insitu: sketching architectural designs in context. ACM Transactions on Graphics, 30(6), 182:1-182:10. https://doi.org/2024156.2024216

Prats, M, Earl, C., Garner, S., \& Jowers, I. (2006). Shape exploration of designs in a style: Toward generation of product designs. Artificial Intelligence for Engineering Design and Manufacturing, 20, 201-215. https://doi.org/10.1017/S0890060406060173

Prats, Miquel, Lim, S., Jowers, I., Garner, S. W., \& Chase, S. (2009). Transforming shape in design: observations from studies of sketching. Design Studies, 30(5), 503-520. https://doi.org/10.1016/j.destud.2009.04.002 
Sansri, S., \& Kielarova, S. W. (2018). Multi-Objective Shape Optimization in Generative Design: Art Deco Double Clip Brooch Jewelry Design. 450. https://doi.org/10.1007/978-981-10-6454-8

Singh, V., \& Gu, N. (2011). Towards an integrated generative design framework. Design Studies, In Press,. https://doi.org/10.1016/j.destud.2011.06.001

Talbott, K. (2007). Context-sensitivity and visual engagement in generative systems. Automation in Construction, 16(1), 54-60. https://doi.org/10.1016/j.autcon.2005.10.009

Tsai, H. C., Chen, T. L., Tsai, H. J., \& Hung, F. K. (2010). Computer-Aided Form Generation for Product Design. Advanced Materials Research, 97-101, 3785-3788. https://doi.org/10.4028/www.scientific.net/AMR.97-101.3785

Wang, L., Chen, K. W., Janssen, P., \& Ji, G. (2020). Enabling optimisation-based exploration for building massing design: A coding-free evolutionary building massing design toolkit in rhino-grasshopper. $R E$ : Anthropocene, Design in the Age of Humans - Proceedings of the 25th International Conference on Computer-Aided Architectural Design Research in Asia, CAADRIA 2020, 1. 